\title{
Concentrações séricas de retinol de éguas gestantes em haras do Vale do Rio Doce e Sul de Minas Gerais
}

\author{
[Retinol serum concentration in pregnant mares in farms of Vale do Rio Doce and \\ Sul de Minas Gerais, Brazil] \\ T.R. Garcia, A.S.C. Rezende*, I.B.M. Sampaio, A.M.Q. Lana, R.S. Moura \\ Escola de Veterinária - UFMG \\ Caixa Postal 567 \\ 30123-970 - Belo Horizonte, MG
}

\begin{abstract}
RESUMO
Foram analisadas as concentrações séricas de retinol de 16 éguas gestantes em haras de duas diferentes regiões de Minas Gerais (Vale do Rio Doce e Sul de Minas). Os animais foram mantidos em pastagens com sal mineral à vontade, sem qualquer suplementação concentrada. Amostras de sangue foram coletadas a cada 30 dias, nos meses de maio a novembro de 2002, objetivando verificar a necessidade de suplementação das éguas com vitamina $\mathrm{A}$ nos meses de seca. A concentração de betacaroteno das pastagens também foi correlacionada com as concentrações sorológicas de vitamina A, a fim de verificar a utilização da reserva hepática dessa vitamina pelos eqüinos. As análises do retinol sorológico e do betacaroteno das pastagens foram realizadas por cromatografia líquida de alta eficiência (HPLC). O experimento foi em parcelas subdivididas, no delineamento inteiramente ao acaso, e os resultados foram comparados pelo teste Duncan. A correlação entre as concentrações séricas de retinol e betacaroteno das pastagens foi estimada pelo método de Pearson. Os resultados demonstraram que, no ano de 2002, não houve necessidade de suplementação das éguas dos haras das regiões estudadas nos meses de seca e que não houve correlação entre os teores de retinol plasmático das éguas com os de betacaroteno das pastagens.
\end{abstract}

Palavras-chave: eqüino, betacaroteno, vitamina $\mathrm{A}$, forragens, nutrição

\section{ABSTRACT}

Retinol serum concentrations were analyzed from 16 pregnant mares raised in farms of two different regions of Minas Gerais state, Brazil (Vale do Rio Doce and Sul de Minas). The animals were maintained on pasture with free access to mineral supplement without grain concentrate supplementation. Blood samples were collected monthly from May to November 2002, aiming to verify the need of vitamin A supplementation during the dry season. The concentration of $\beta$-carotene from pasture samples was also correlated with blood plasma concentration to verify the utilization of hepatic stock of vitamin A. High performance liquid chromatography (HPLC) was used to determine vitamin $A$ and $\beta$-carotene concentrations. The used statistics was the split plot design and the results were compared by Duncan test. The Pearson correlation between the serum concentration of retinol and $\beta$-carotene from pasture was estimated. The results demonstrated that the supplementation of pregnant mares in farms of the studied regions was not necessary during the dry season and that no significant correlation between the serum concentration of retinol and $\beta$-carotene from pasture was observed.

Keywords: equine, $\beta$-carotene, vitamin A, forages, nutrition, retinol

Recebido em 9 de janeiro de 2006

Aceito em 20 de novembro de 2006

*Autor para correspondência (corresponding author)

E-mail: adalgiza@vet.ufmg.br

Apoio: FAPEMIG 


\section{INTRODUÇÃO}

A vitamina A é um importante nutriente na alimentação dos eqüinos, pois exerce múltiplas funções relacionadas à fisiologia normal do organismo (Carneiro, 1982). É fundamental para a visão, reprodução, manutenção do epitélio, crescimento e saúde. As maiores fontes dessa vitamina são as forrageiras que, quando verdes, são ricas em carotenóides, os quais são parcialmente convertidos em retinol na mucosa intestinal, sendo o betacaroteno o principal precursor. Pastagens no final do ciclo vegetativo apresentam baixo teor dessa pró-vitamina, devido a sua progressiva deterioração. Nessas condições, as necessidades de vitamina $\mathrm{A}$ dos animais nem sempre são supridas (Meyer, 1995).

Os eqüinos dependem do alimento como única fonte de vitamina A (Izaguirre e Miyasaka, 2001) e, segundo Greiwe-Crandell et al. (1997), a eficiência de conversão do betacaroteno em vitamina A é, relativamente, pequena na espécie eqüina. A conversão de betacaroteno em retinol na mucosa intestinal diminui proporcionalmente ao aumento das concentrações dessa próvitamina na dieta e pode variar de acordo com a espécie de forrageira ingerida pelos animais (Nutrient..., 1989).

Para Blakley e Bell (1994), a suplementação com vitamina $\mathrm{A}$, provavelmente, não é requerida por eqüinos que recebem forragens frescas ou são mantidos a pasto. Éguas mantidas em pastagens no inverno não apresentaram queda no status de vitamina A como as que permaneceram em cocheiras, ressaltando que a forma natural do betacaroteno nas pastagens, solúvel em óleo, facilita absorção intestinal (Greiwe-Crandell et al., 1997). De acordo com o National Research Council (Nutrient..., 1989), a suplementação com betacaroteno não é necessária em éguas mantidas a pasto ou que estejam sendo alimentadas com forragens que apresentem altos teores de betacaroteno.

Garton et al. (1964), Jarret e Schurg (1987), Mäenpää et al. (1988a), Mcdowell (1989), Bakley e Bell (1994) e Greiwe-Crandell et al. (1995) relataram redução do retinol sangüíneo de eqüinos durante o período de seca em decorrência da baixa concentração de betacaroteno nas forragens oferecidas a esses animais. Os eqüinos são capazes de armazenar no fígado a vitamina A ingerida durante os períodos de pastagens verdes (Nutrient..., 1989), mas algumas regiões de Minas
Gerais sofrem com extensos períodos de seca, o que leva ao esgotamento da reserva hepática dessa vitamina, predispondo os animais a sua deficiência (Pereira, 2000).

De acordo com o National Research Council (Nutrient..., 1989), éguas gestantes e em lactação apresentam exigências nutricionais de vitamina A maiores que as outras categorias de eqüinos, concordando com a citação de Mäenpää et al. (1988a), de que a variação sazonal das concentrações séricas de retinol em éguas gestantes foram consideravelmente maiores que em éguas não gestantes e machos adultos em treinamento. O tipo de placenta da égua (microcotiledonária) faz com que a transferência de retinol para o feto via transplacentária seja ineficiente (Cunha, 1991) e para satisfazer as necessidades nutricionais de vitamina A, garantindo seu perfeito desenvolvimento, o potro é totalmente dependente dessa vitamina presente no colostro (Meyer, 1995; Schweigert e Gottwald, 1999). Greiwe-Crandell et al. (1996) relataram que potros apresentaram deficiência de vitamina $A$ ao nascimento, com baixas concentrações plasmáticas de retinol, o que melhorou rapidamente com a ingestão do colostro. Esses autores ressaltaram que o tempo de absorção da vitamina A no intestino dos recém-nascidos coincide com o das imunoglobulinas.

Esse trabalho foi realizado, visando avaliar as possíveis variações sazonais das concentrações séricas de retinol em éguas gestantes criadas em haras de duas diferentes regiões do estado de Minas Gerais, Vale do Rio Doce e Sul de Minas, objetivando verificar a necessidade de suplementação dessa vitamina e a melhor época para sua realização.

\section{MATERIAL E MÉTODOS}

O presente trabalho foi conduzido de maio a novembro de 2002, em dois haras do Vale do Rio Doce: Haras do Encanto e Fazenda Acesita, ambos situados no município de Matias Lobato, MG e em dois haras do Sul de Minas: Haras Porteira de Tábua e Haras Monjolinho, situados nos municípios de Três Pontas, MG e Santana da Vargem, MG, respectivamente. O período experimental durou sete meses e durante este período, em cada haras foram colhidas amostras sangüíneas mensais de quatro 
éguas gestantes da raça Mangalarga Marchador, totalizando 16 animais, oito em cada região. No início do período experimental, as médias de idade, período de gestação, peso vivo estimado ${ }^{1}$ e escore corporal avaliado de acordo com Carrol e Huntington (1988), foram 85 meses, 146 dias, $495 \mathrm{~kg}$ e 3,94 respectivamente, para as éguas do Vale do Rio Doce e 84 meses, 120 dias, $425 \mathrm{~kg}$ e 3,13 , respectivamente, para as éguas do Sul de Minas. Os animais foram mantidos a pasto sem qualquer suplementação volumosa ou concentrada, recebendo somente sal mineral, estes com ausência de carotenóides e/ou vitamina A na sua composição. No Haras Porteira de Tábua, a pastagem era constituída de Melinis minutiflora (capim-gordura) e Paspalum notatum (gramabatatais). No Haras Monjolinho, de Brachiaria humidicula (humidícola), Brachiaria radicans (braquiária-do-brejo) e Paspalum notatum (gramabatatais). No Haras do Encanto, assim como na Fazenda Acesita, as pastagens eram constituídas de Panicum maximum c.v. Colonião. As taxas de lotação dos lotes de éguas nas pastagens foram de 0,$40 ; 0,36 ; 0,75$ e 0,38 cabeça/hectare nos Haras Porteira de Tábua, Monjolinho, do Encanto e Fazenda Acesita, respectivamente.

As amostras de sangue foram colhidas, com intervalos médios de 30 dias, a partir de 21/05/2002 até 30/11/2002 em ambas as regiões, por meio de punção na veia jugular, utilizando-se tubos do tipo Vacutainer $^{2}$ de $10 \mathrm{ml}$, os quais após a colheita, foram imediatamente armazenados em recipiente escuro, protegidos da luz. Em seguida, as amostras de sangue foram centrifugadas por 20 minutos a $3000 \mathrm{rpm}$ para extração do soro, sendo este acondicionado em tubos Eppendorf de $2 \mathrm{ml}$ de cor âmbar, embalados em papel alumínio, imediatamente resfriado e congelado a $-20^{\circ} \mathrm{C}$, até o momento das análises. Amostras das pastagens foram colhidas manualmente, simulando o hábito de pastejo dos eqüinos, de acordo com a técnica descrita por Gardner (1986). Uma fração do pool de pastagem foi acondicionada em saco plástico, envolvida com papel alumínio e congelada a $-20^{\circ} \mathrm{C}$ para posterior análise do teor de betacaroteno. $\mathrm{O}$ restante do pool foi também acondicionado em saco plástico e congelado para posterior análise bromatológica. A extração e leitura para quantificação da vitamina A no soro foram realizadas no Setor de HPLC do Laboratório Hermes Pardini, Belo Horizonte, Minas Gerais, de acordo com adaptações na metodologia de Pesce e Kaplan (1987). A extração e leitura do betacaroteno

${ }^{1} \mathrm{PC}=\mathrm{PT}^{3} \mathrm{x} 80$, onde $\mathrm{PT}=$ perímetro torácico $(\mathrm{Val}, 1989)$

${ }^{2}$ Venoject das forragens foram realizadas de acordo com adaptações no método oficial da AOAC Internacional (Official..., 1995), no Laboratório de Cromatografia do Departamento de Química do Instituto de Ciências Exatas-UFMG. As análises bromatológicas das amostras de pastagens foram realizadas no Laboratório de Nutrição Animal da Escola de Veterinária-UFMG.

Foram utilizados, para as análises de betacaroteno, um cromatógrafo líquido de alta eficiência $(\text { HPLC })^{3}$, coluna analítica ${ }^{4}$, bomba isocrática ${ }^{5}$, injetor $^{6}$, detector de ultra-violeta $(\mathrm{UV})^{7}$ com comprimento de onda de $450 \mathrm{~nm}$, software ${ }^{8}$ e ultrasom $^{9}$. Para as análises de retinol no soro das éguas foram utilizados: cromatógrafo líquido de alta eficiência (HPLC) $^{3}$, coluna analítica $^{10}$, bomba isocrática $^{11}$, injetor ${ }^{12}$, detector ultravioleta (UV) ${ }^{13}$ com comprimento de onda de $280 \mathrm{~nm}$ e software ${ }^{14}$. Utilizou-se hexano ${ }^{15}$ e metanol ${ }^{15}$, ambos grau HPLC, éter etílico (PA) ${ }^{15}$, acetona ${ }^{16}$ e carbonato de magnésio. Para as análises de retinol sérico foi utilizado o todo-trans-retinol ${ }^{17}$ como padrão externo e para as análises de betacaroteno nas pastagens, $o$ padrão externo foi o todo-trans-betacaroteno ${ }^{18}$.

O experimento foi em parcelas subdivididas, com duas parcelas (regiões), sete sub-parcelas (meses de colheita) no delineamento inteiramente ao acaso, com oito repetições (éguas) em cada região. A comparação das médias das concentrações séricas de retinol e das de betacaroteno nas pastagens, durante os meses do experimento, foi realizada utilizando o teste Duncan (Sistema..., 2000). Para a análise estatística das concentrações de betacaroteno, foi realizada transformação de dados utilizando a função raiz quadrada de "betacaroteno +1 ", para alcançar a normalidade e homogeneidade das variâncias de tratamentos. Foi estimada a correlação de Pearson entre as variáveis retinol sérico e betacaroteno das pastagens.

\footnotetext{
${ }^{3}$ Shimadzu

${ }^{4}$ ODS Hypersil $3 \mu \mathrm{m} 60$ x 4.6 mm (HP)

${ }^{5}$ Shimadzu LC 10 AD

${ }^{6}$ Rheodyne

${ }^{7}$ Shimadzu SPD 10 A

${ }^{8}$ Class LC 10

${ }^{9}$ Branson 1510 E-MT

${ }^{10}$ Nova Pak C18 $150 \times 3.9 \mathrm{~mm}$

${ }^{11}$ Waters 515

${ }^{12}$ Rheodyne

${ }^{13}$ Waters 2487

${ }^{14}$ Empower

${ }^{15}$ Isofar

${ }^{16}$ Quimex

${ }^{17}$ Sigma R 7632

${ }^{18}$ Sigma C 9750
} 


\section{RESULTADOS E DISCUSSÃO}

Para Baker et al. (1986); Mäenpaa et al. (1987; 1988a); National Research Council (Nutrient..., 1989); Meyer (1995) e Lewis (2000), concentrações sorológicas de retinol abaixo de $10 \mu \mathrm{g} / \mathrm{dl}$ nos eqüinos, indicam deficiência de vitamina A.
Na Tab. 1 pode-se observar que durante todo o período estudado, não houve deficiência de vitamina nas duas regiões avaliadas e não houve diferença $(\mathrm{P}>0,05)$ na concentração de retinol sérico das éguas, entre os diferentes meses, em cada região.

Tabela 1. Concentrações de retinol $(\mu \mathrm{g} / \mathrm{dl})$ no soro de éguas gestantes, durante os meses de seca, em duas diferentes regiões de Minas Gerais

\begin{tabular}{lccccccc}
\hline \multirow{2}{*}{ Região } & \multicolumn{7}{c}{ Meses } \\
\cline { 2 - 7 } & Mai & Jun & Jul & Ago & Set & Out & Nov \\
\hline Sul de Minas & $16,21 \pm 4,84$ & $14,20 \pm 6,13$ & $12,56 \pm 5,35$ & $10,61 \pm 5,99$ & $13,10 \pm 6,37$ & $13,14 \pm 6,16$ & $11,10 \pm 3,64$ \\
\hline Vale do Rio Doce & $14,55 \pm 5,60$ & $14,43 \pm 5,48$ & $11,56 \pm 3,37$ & $13,26 \pm 3,69$ & $16,24 \pm 4,85$ & $16,48+4,84$ & $16,85 \pm 6,41$ \\
\hline
\end{tabular}

$\overline{\mathrm{CV}}=36,51 \%$

Para Blakley e Bell (1994), a suplementação com vitamina A provavelmente não é requerida por eqüinos que recebem forragens frescas ou são mantidos no pasto. O Brasil é um país de clima tropical e, portanto na época considerada como período seco (outono e inverno), não apresenta ausência total de chuvas como ocorre nos países de clima frio.

As características climáticas das regiões estudadas durante o ano de 2002 estão na Tab. 2, onde pode-se observar que no ano do presente trabalho (2002) houve ausência total de chuvas nos meses de abril, junho e julho na região do Vale do Rio Doce e praticamente não houve ausência de chuvas no Sul de Minas. Nessa última região, de junho a agosto, houve pouca chuva, mas apenas no mês de junho houve ausência total de precipitação. De acordo com Carvalho e Alvim (2000), apesar da precipitação ser considerada o fator mais importante para o crescimento e desenvolvimento das plantas forrageiras, as curvas de umidade relativa do ar e temperatura também influenciam diretamente nesse desenvolvimento.

De acordo com Gomide (1988), as forrageiras consumidas pelas éguas avaliadas no presente trabalho estão adaptadas às condições de clima e solo do estado de Minas Gerais, o que associado às características climáticas e principalmente, aos índices pluviométricos das regiões estudadas
(Tab. 2) ofereceram condições para o crescimento vegetativo das plantas durante $\mathrm{o}$ período de seca do ano de 2002. Essa observação, associada às baixas taxas de lotação dos piquetes utilizados nos haras, mostra que as éguas tiveram acesso a pastagens verdes e frescas durante todo o período experimental. Essas condições sugerem não haver necessidade de suplementar com vitamina A o rebanho eqüídeo, durante o período de seca, tanto no Sul de Minas quanto no Vale do Rio Doce.

De acordo com Meyer (1995), as maiores fontes de vitamina A são as forrageiras quando verdes, as quais apresentam elevados teores de betacaroteno. Esse autor ressaltou que os teores de pró-vitamina $\mathrm{A}$, presentes nas pastagens verdes e frescas, variam de 50 a $75 \mathrm{mg} / \mathrm{kg}$ na matéria natural. No trabalho de Guimarães et al. (1992) foram encontrados valores que variaram de 145 a $524 \mathrm{mg}$ de betacaroteno/ $\mathrm{kg}$ de matéria natural em pastagens de Brachiaria decumbens durante os meses de seca no estado de Minas Gerais.

No período de maio a novembro de 2002 (Tab. 3 ), as concentrações médias de betacaroteno nas pastagens do Sul de Minas e Vale do Rio Doce variaram de 124 a $225 \mathrm{mg} / \mathrm{kg}$ e de 91 a $434 \mathrm{mg} / \mathrm{kg}$ de matéria natural, respectivamente, valores também superiores aos citados por Meyer (1995). 


\section{Garcia et al.}

Tabela 2. Precipitação (P), umidade relativa do ar (URA) e temperatura média (T) de duas regiões de Minas Gerais (Sul de Minas e Vale do Rio Doce), durante o ano de 2002

\begin{tabular}{|c|c|c|c|c|c|c|}
\hline \multirow{3}{*}{ Mes } & \multicolumn{6}{|c|}{ Índice climatológico } \\
\hline & \multicolumn{3}{|c|}{ Sul de Minas } & \multicolumn{3}{|c|}{ Vale do Rio Doce } \\
\hline & $\begin{array}{c}\mathrm{P} \\
(\mathrm{mm})\end{array}$ & URA $(\%)$ & $\begin{array}{c}\mathrm{T} \\
\left({ }^{\circ} \mathrm{C}\right) \\
\end{array}$ & $\begin{array}{c}\mathrm{P} \\
(\mathrm{mm})\end{array}$ & URA $(\%)$ & $\begin{array}{c}\mathrm{T} \\
\left({ }^{\circ} \mathrm{C}\right) \\
\end{array}$ \\
\hline Janeiro & 255 & 76 & 22,8 & 304 & 78 & 26,6 \\
\hline Fevereiro & 364 & 82 & 21,7 & 151 & 79 & 26,1 \\
\hline Março & 52,5 & 76 & 22,8 & 140 & 75 & 26,2 \\
\hline Abril & 18 & 66 & 22,2 & 0 & 72 & 26,0 \\
\hline Maio & 96,5 & 72 & 19,6 & 36 & 76 & 23,6 \\
\hline Junho & 0 & 64 & 18,6 & 0 & 77 & 22,0 \\
\hline Julho & 21 & 67 & 17,7 & 0 & 73 & 22,4 \\
\hline Agosto & 11,5 & 57 & 20,4 & 60 & 70 & 19,6 \\
\hline Setembro & 61,5 & 66 & 19,6 & 80 & 79 & 23,5 \\
\hline Outubro & 53 & 53 & 23,8 & 7 & 62 & 26,1 \\
\hline Novembro & 168 & 71 & 22,4 & 167 & 72 & 25,5 \\
\hline Dezembro & 134 & 76 & 23,7 & 329 & 77 & 26,6 \\
\hline TOTAL & 1235 & - & - & 1274 & - & - \\
\hline MÉDIA & - & 69 & 21,3 & - & 74 & 24,5 \\
\hline
\end{tabular}

Fonte: Departamento de café da Cooperativa dos Cafeicultores de Três Pontas (Cocatrel), Instituto de Meteorologia (INMET) e Fazenda Acesita.

Tabela 3. Concentração de betacaroteno ( $\mathrm{mg} / \mathrm{kg}$ de matéria natural) nas pastagens, durante os meses de Maio a Novembro de 2002, em duas diferentes regiões de Minas Gerais

\begin{tabular}{lccccccc}
\hline \multirow{2}{*}{ Região } & \multicolumn{7}{c}{ Mês } \\
\cline { 2 - 8 } Sul de Minas & Mai & Jun & Jul & Ago & Set & Out & Nov \\
\hline \multirow{2}{*}{ Vale do Rio Doce } & $124 \mathrm{Aa}$ & $225 \mathrm{Aa}$ & $209 \mathrm{Aa}$ & $215 \mathrm{Aa}$ & $179 \mathrm{Aa}$ & $220 \mathrm{Aa}$ & $221 \mathrm{Ab}$ \\
& $91 \mathrm{Da}$ & $224 \mathrm{BCa}$ & $309 \mathrm{Ba}$ & $178 \mathrm{CDa}$ & $299 \mathrm{Ba}$ & $268 \mathrm{BCa}$ & $434 \mathrm{Aa}$
\end{tabular}

Médias seguidas por letras maiúsculas distintas na linha ou minúsculas na coluna diferem entre si $(\mathrm{P}<0,05)$ $\mathrm{CV}=4,98 \%$

A escassez de chuvas no Vale do Rio Doce, nos meses de abril, junho e julho (Tab. 2) trouxe como conseqüência redução na concentração de betacaroteno $(\mathrm{P}<0,05)$ nas pastagens dos haras dessa região nos meses de maio e agosto (Tab. 3). Entretanto, os teores de retinol no soro das éguas (Tab. 1) não acompanharam esta redução $(\mathrm{P}>0,05)$, o que pode ser explicado por uma possível utilização da vitamina A estocada no fígado desses animais. As demais diferenças $(\mathrm{P}<0,05)$ observadas na concentração de betacaroteno das pastagens do Vale do Rio Doce refletem a instabilidade das chuvas na região. Já no Sul de Minas, pode-se observar que a deficiência de chuvas não foi suficiente para afetar as concentrações de betacaroteno nas pastagens dos haras estudados $(\mathrm{P}>0,05)$.

O coeficiente de correlação (r) entre as concentrações de retinol no soro das éguas e as de betacaroteno das forragens das regiões estudadas foi negativo, com valores, para o Sul de Minas e Vale do Rio Doce de: - 0,0113 e 0,0061 , respectivamente. Greiwe-Crandell et al. (1997) relataram que a eficiência de conversão do betacaroteno em vitamina A é relativamente pequena na espécie eqüina e Nunes (1998) enfatizou que quanto maior o teor de 
betacaroteno na dieta, menor é a conversão e absorção dessa pró-vitamina. A alta disponibilidade de beta caroteno nas pastagens dos haras do Sul de Minas, durante todo o período estudado (Tab. 3), pode ter limitado a conversão e absorção de retinol na mucosa intestinal, determinando a ausência de correlação.

No Vale do Rio Doce, houve variação das concentrações de betacaroteno durante os meses estudados e não houve alteração dos teores plasmáticos de retinol nas éguas dessa região. Essa diferença pode também ser explicada pela baixa conversão e absorção de retinol na mucosa intestinal ou por uma possível utilização da reserva hepática de vitamina A para manter os teores plasmáticos de betacaroteno dentro dos padrões, determinando a ausência da correlação.

\section{CONCLUSÕES}

Nos haras das regiões do Sul de Minas e do Vale do Rio Doce parece não haver necessidade de suplementar o rebanho eqüino mantido em pasto com vitamina $\mathrm{A}$, durante o período de seca. Não houve correlação significativa entre a concentração da pró-vitamina A presente nas pastagens e as concentrações séricas de retinol, sugerindo que os eqüinos utilizam a reserva de vitamina A do organismo. Mais estudos são necessários para avaliar a capacidade da reserva de vitamina $\mathrm{A}$ no fígado dos eqüinos, a fim de definir a real necessidade e a melhor época de suplementação do rebanho eqüino com essa importante vitamina.

\section{REFERÊNCIAS BIBLIOGRÁFICAS}

BAKER, H.; SCHOR, S.M.; MURPHY, B.D. et al. Blood vitamin and choline concentrations in healthy domestic cats, dogs and horses. Am. J. Vet. Res., v.47, p.1468-1471, 1986.

BLAKLEY, B.R.; BELL, R.J. The vitamin A and vitamin $\mathrm{E}$ status of horses raised in Alberta and Saskatchewan. Can. Vet. J., v.35, p.297-300, 1994.

CARNEIRO, A.S. Vitamina A na alimentação de eqüídeos. 1982. 14f. Seminário. Departamento de Medicina Veterinária, Universidade Federal do Mato Grosso do Sul. Campo Grande, MS.
CARROL, C.L.; HUNTINGTON, P.J. Body condition scoring and weight estimation of horses. Equine Vet. J., v.20, p.41-45, 1988.

CARVALHO, M.M.; ALVIM, M.J. Pastagens para gado de leite em regiões de influencia da mata atlântica. Juiz de Fora: Embrapa Gado de Leite, 2000. 178p.

CUNHA, T.J. Horse feeding and nutrition. 2.ed. San Diego: Academic, 1991. 445p.

GARDNER, A.L. Técnicas de pesquisa em pastagens e aplicabilidade de resultados em sistemas de produção. Brasília: IICA/Embrapa, 1986. $197 \mathrm{p}$.

GARTON, C.L.; VANDER NOOT, G.W.; FONNESBECK, P.V. Seasonal variation in carotene and vitamin concentrations of the blood of brood mares in New Jersey. J. Anim. Sci., v.23, p.1233, 1964. (Abstr.).

GOMIDE, J.A. Sistemas de manejo de gramíneas do gênero Melinis. In: SIMPÓSIO SOBRE MANEJO DA PASTAGEM, 9., 1988, Piracicaba, Anais... Piracicaba: FEALQ, 1988. p.41-55.

GREIWE-CRANDELL, K.M.; KRONFELD, D.S.; GAY, L.A. et al. Seasonal vitamin A depletion in grazing horses is assessed better by the relative dose response test than by serum retinol concentration. J. Nutr., v.125, p.2711-2716, 1995.

GREIWE-CRANDELL, K.M.; KRONFELD, D.S.; GAY, L.S. et al. Vitamin A status of neonatal foals assessed by serum retinol concentration and a relative dose response test. Pferdeheilkunde, v.12, p.181-183, 1996.

GREIWE-CRANDELL, K.M.; KRONFELD, D.S.; GAY, L.A. et al. Vitamin A repletion in Thorougbred mares with retinyl palmitate or Bcarotene. J. Anim. Sci., v.75, p.2684-2690, 1997.

GUIMARÃES, A.M.; SALIBA, E.O.S.; RODRIGUES, N.M. et al. Variação sazonal de vitamina $A$, macro e microelementos no capim, plasma e fígado de novilhas nelore, criadas em pastagens de capim braquiária (Brachiaria decumbens). Arq. Bras. Med. Vet. Zootec., v.44, p.57-66, 1992.

IZAGUIRRE, O.M.; MIYASAKA, A.S. Causas del color amarillo de la grasa de canales de bovinos finalizados en pastoreo. Vet. Mex., v.32, p.63-71, 2001.

JARRET, S.H.; SCHURG, W. Use of a modified relative dose response test for determination of 
vitamin A status in horses. Nutr. Rep. Int., v.35, p.733-742, 1987.

LEWIS, L.D. Nutrição clínica eqüina: alimentação e cuidados. São Paulo: Roca, 2000. $446 \mathrm{p}$.

MÄENPÄÄ， P.H.; LAPPETELAINEM， R.; VIRKKUNEM, J. Serum retinol, 24hydroxyvitamin $\mathrm{D}$ and $\alpha$-tocopherol of racing trotters in Finland. Equine Vet. J., v.19, p.237$240,1987$.

MÄENPÄÄ, P.H.; KOSKINEN, T.; KOSKINEN, E. Serum profiles of vitamin A, E and $\mathrm{D}$ in mares and foals during different seasons. J. Anim. Sci., v.66, p.1418-1423, 1988 a.

MCDOWELL, L.R. Vitamin A. In: Vitamins in animal nutrition, comparative aspects to human nutrition. San Diego: Academic, 1989. p.20.

MEYER, H. Alimentação de cavalos. São Paulo: Varela, 1995. 303p.

NUNES, I.J. Nutrição animal básica. Belo Horizonte: FEPMVZ, 1998. 388p.
NUTRIENT requeriments of horses. 5.ed. Washington: National Academy, 1989. 100p.

OFFICIAL Methods of Analysis. 16.ed. Washington: AOAC, 1995.

PEREIRA, F.N. Avaliação da concentração sérica de retinol em éguas gestantes a pasto, durante o período de seca, em duas regiões de Minas Gerais. 2000. 36f. Dissertação (Mestrado em Zootecnia) - Escola de Veterinária, Universidade Federal de Minas Gerais, Belo Horizonte.

PESCE, A.J.; KAPLAN, L.A. Methods in clinical chemistry. Washington: C. V. Mosby, 1987. p. 587-590.

SCHWEIGERT, F.J.; GOTTWALD, C. Effect of parturition on levels of vitamin $A$ and $E$ and of $\beta$ carotene in plasma and milk of mares. Equine Vet. J., v.31, p.319-323, 1999.

SISTEMA de análises estatísticas e genéticas. Versão 8.0. Viçosa: UFV, 2000.

VAL, L.J.L. $O$ exterior dos eqüídeos. Belo Horizonte: FEPMVZ, 1989. 76p. 